\title{
COVID-19 in Poland: potential associations with epidemiology, population and healthcare quality
}

Katarzyna Orlewska ${ }^{1,2}$, Justyna Klusek ${ }^{3}$

\begin{abstract}
${ }^{1}$ Faculty of Health Sciences, Medical University of Warsaw, Warsaw, Poland 2Department of Internal Medicine, Tytus Chałubiński's Hospital, Zakopane, Poland ${ }^{3}$ Department of Surgical Medicine, with the Laboratory of Medical Genetics, Collegium Medicum, Jan Kochanowski University, Kielce, Poland
\end{abstract}

Submitted: 4 June 2020

Accepted: 23 July 2020

Arch Med Sci

DOI: https://doi.org/10.5114/aoms.2020.98236

Copyright (c) 2020 Termedia \& Banach

\section{Abstract}

Introduction: An attempt to assess basic epidemiological data was made two months after confirming the first case of SARS-CoV-2 in Poland (March $4^{\text {th }}$, 2020). The aim of the study was to examine which indicators related to epidemiology, population characteristics and health care quality affect COVID-19 incidence, mortality and case fatality in Poland.

Material and methods: The study was based on national data as of May $4^{\text {th }}, 2020$. For each voivodeship incidence rates, mortality rates, case fatality rates and daily cumulative index $(\mathrm{DCl})$ were calculated. The correlations were examined using Pearson's and Spearman's rank correlation coefficient, with a significance level of $p<0.05$ (2-tailed tests).

Results: The overall COVID-19 incidence rate was 3.65 per 10,000 population, mortality rate 0.18 per 10,000 population and case fatality rate $5 \%$. All three disease indicators were positively correlated with $\mathrm{DCl}$ and negatively correlated with the number of hospital beds in infectious diseases wards per 10,000 population. Both incidence and mortality rates were positively correlated with population density and number of cases per COVID-19 designated hospital.

Conclusions: The positive correlation between $\mathrm{DCl}$ and both mortality and case fatality suggests that $\mathrm{DCl}$ could be considered as an indirect indicator of healthcare burden, compared to incidence rate alone. Our analysis confirms the role of social distancing in reducing viral transmission. The results could be useful for policymakers to plan ahead in order to relieve the risk of healthcare system overload during the current and future epidemics.

Key words: COVID-19, epidemiology, incidence, mortality.

\section{Introduction}

The first laboratory confirmed case of SARS-CoV-2 in Poland was announced on March $4^{\text {th }}, 2020$ [1]. On March 10 th the mode of SARS-CoV-2 transmission in Poland was officially declared by the World Health Organization as having shifted from imported cases only to local transmission [2]. In order to limit viral transmission, Polish authorities initiated lockdown type measures in mid-March. An official epidemic was declared on March $20^{\text {th }}$ [3]. According to the Main Sanitary Inspectorate, meeting the suspect case definition for COVID-19 is an indication for laboratory testing in order to confirm or exclude a diagnosis. A suspected COVID-19

\author{
Corresponding author: \\ Katarzyna Orlewska MD \\ Faculty of Health Sciences \\ Medical University of Warsaw \\ 61 Żwirki i Wigury St \\ 02-091 Warsaw, Poland \\ Phone: +48 600468365 \\ E-mail: korlewska@gmail.com
}


case is defined as a person meeting one of the following criteria [4]:

- presenting group A clinical symptoms (cough, fever, shortness of breath) without other confirmed etiology and staying or returning from an area with local or low-frequency COVID-19 transmission within the last 14 days or having close contact with a confirmed COVID-19 case,

- being hospitalized with symptoms of severe respiratory infection without other confirmed etiology or presenting life or health threatening symptoms of respiratory failure.

A confirmed COVID-19 case is defined as a positive result of real-time reverse-transcriptase-polymerase-chain-reaction (RT-PCR) assay of nasal or pharyngeal swab specimens. Official case fatality rates in Poland initially included only deaths of confirmed COVID-19 cases (U07.1 according to the ICD-10). Since April $1^{\text {st }}$, in keeping with a report published by the National Institute of Public Health, fatalities that were clinically or epidemiologically diagnosed as COVID-19 (U07.2) were also considered as deaths due to COVID-19 [5].

The aim of this study was to analyze the basic COVID-19 epidemiological data on a regional level and to examine which indicators related to epidemiology, population characteristics and healthcare quality affect COVID-19 incidence, mortality and case fatality in Poland. The results may potentially help to better understand the epidemiology of COVID-19 and could be useful for policymakers to plan ahead in order to relieve the risk of overload of the healthcare system.

\section{Material and methods}

Poland is made up of 16 voivodeships, which represent the highest level of administrative subdivision. This division was used in the study to portray geographical variety within the country. The study was based on national data as of May $4^{\text {th }}$, 2020: epidemiological data (number of confirmed cases and deaths, number of performed tests, dates of the first confirmed case) from all 16 voivodeships have been retrieved from official coronavirus source data [6]; data on population, population density, proportion of urban population and proportion of population aged above 65 for each voivodeship were obtained from Statistics Poland reports [7]; indicators used to characterize voivodeships in terms of the healthcare system performance (healthcare performance index, health consumer index, effective financial management index) were derived from a report published by PricewaterhouseCoopers Poland [8]; the number of hospitals with isolation wards in each voivodeship were retrieved from the list of hospitals published by the Ministry of Health [9]; the number of beds in general hospitals per
10,000 population and the number of beds in infectious disease wards by voivodeships were obtained from Statistics Poland [10] and voivodeship office reports [11].

For each voivodeship morbidity indicator (incidence rate, i.e. COVID-19 cases per 10,000 population), death rate indicator (mortality rate, i.e. number of people who have died due to COVID-19 per 10,000 population), disease severity indicator (case fatality rate, i.e. proportion of deaths among patients with COVID-19) and DCI (daily cumulative index, defined as cumulative cases divided by the number of days between the first reported case and May $\left.4^{\text {th }}, 2020\right)$ were calculated.

Pearson's correlation coefficient (PCC) and Spearman's rank correlation coefficient (SRCC) were used to examine the links between incidence, mortality, case fatality and various epidemiological indicators. PCC is typically used to evaluate the linear relationship between normally distributed variables. For nonnormally distributed data, ordinal data or data with relevant outliers, SRCC is more appropriate. Both correlation coefficients range in value from -1 to +1 . When it equals 1 the two variables perfectly correlate in a positive way, when it equals 0 they are independent from one another, and when it equals -1 they perfectly correlate in a negative way (anti-correlation). The strength of association between the two variables is considered very strong if the coefficient ranges from 0.8 to 1 , moderate (or strong) if it ranges from 0.5 to 0.8 , weak (or fair) if it ranges from 0.2 to 0.5 , and very weak (or poor) when it is less than 0.2 .

\section{Statistical analysis}

The correlation was considered statistically significant if the $p$-value was equal to or less than the significance level of 0.05 (2-tailed tests).

\section{Results}

As of May $4^{\text {th }}$, nearly 10,000 people in a million have been tested, a total of 14,006 cases have been confirmed, and 697 persons have died due to COVID-19 in Poland. The mean age of death among women was 77.6 (the youngest registered deceased patient was 27 years old) and among men it was 72.3 (the youngest registered deceased patient was 18 years old). The overall incidence rate was 3.65 per 10,000 population, mortality rate 0.18 per 10,000 population and case fatality rate $5 \%$.

COVID-19 incidence, mortality and case fatality rates and number of performed tests for individual voivodeships, grouped by population density, are presented in Table I. Individual voivodeships and corresponding $\mathrm{DCl}$ are presented in Figure 1. The highest incidence per 10,000 population was 
Table I. Incidence, mortality and case fatality rates and number of performed tests for individual voivodeships, grouped by population density

\begin{tabular}{|lcccccc|}
\hline Voivodeship & $\begin{array}{c}\text { Population } \\
\text { density/km }\end{array}$ & DCl & Tests/1,000 & $\begin{array}{c}\text { Cases/ } \\
10,000\end{array}$ & $\begin{array}{c}\text { Deaths/ } \\
10,000\end{array}$ & $\begin{array}{c}\text { Deaths/ } \\
\text { cases }\end{array}$ \\
\hline Silesian & 368 & 86.67 & 7.15 & 5.86 & 0.29 & 0.05 \\
\hline Lesser Poland & 224 & 16.64 & 7.74 & 2.87 & 0.09 & 0.03 \\
\hline Masovian & 152 & 44.71 & 21.31 & 4.72 & 0.39 & 0.08 \\
\hline Lower Silesian & 145 & 30.92 & 9.39 & 5.94 & 0.18 & 0.03 \\
\hline Lodz & 135 & 18.49 & 11.03 & 4.33 & 0.13 & 0.03 \\
\hline Pomeranian & 127 & 7.51 & 11.11 & 1.9 & 0.08 & 0.04 \\
\hline Subcarpathian & 119 & 8.50 & 5.11 & 1.71 & 0.11 & 0.07 \\
\hline Greater Poland & 117 & 25.56 & 9.72 & 4.38 & 0.27 & 0.06 \\
\hline Kuyavian-Pomeranian & 116 & 9.11 & 5.26 & 2.68 & 0.14 & 0.05 \\
\hline Holy Cross & 106 & 5.98 & 9.01 & 2.27 & 0.06 & 0.03 \\
\hline Opole & 105 & 8.04 & 3.92 & 4.41 & 0.29 & 0.07 \\
\hline Lublin & 84 & 6.49 & 7.83 & 1.77 & 0.07 & 0.04 \\
\hline West Pomeranian & 74 & 7.38 & 5.38 & 2.52 & 0.08 & 0.03 \\
\hline Lubusz & 73 & 1.37 & 5.71 & 0.89 & 0 & 0 \\
\hline Podlaskie & 59 & 6.22 & 11.07 & 3.2 & 0.04 & 0.01 \\
\hline Warmian-Masurian & 59 & 2.36 & 9.88 & 1.05 & 0.01 & 0.01 \\
\hline
\end{tabular}
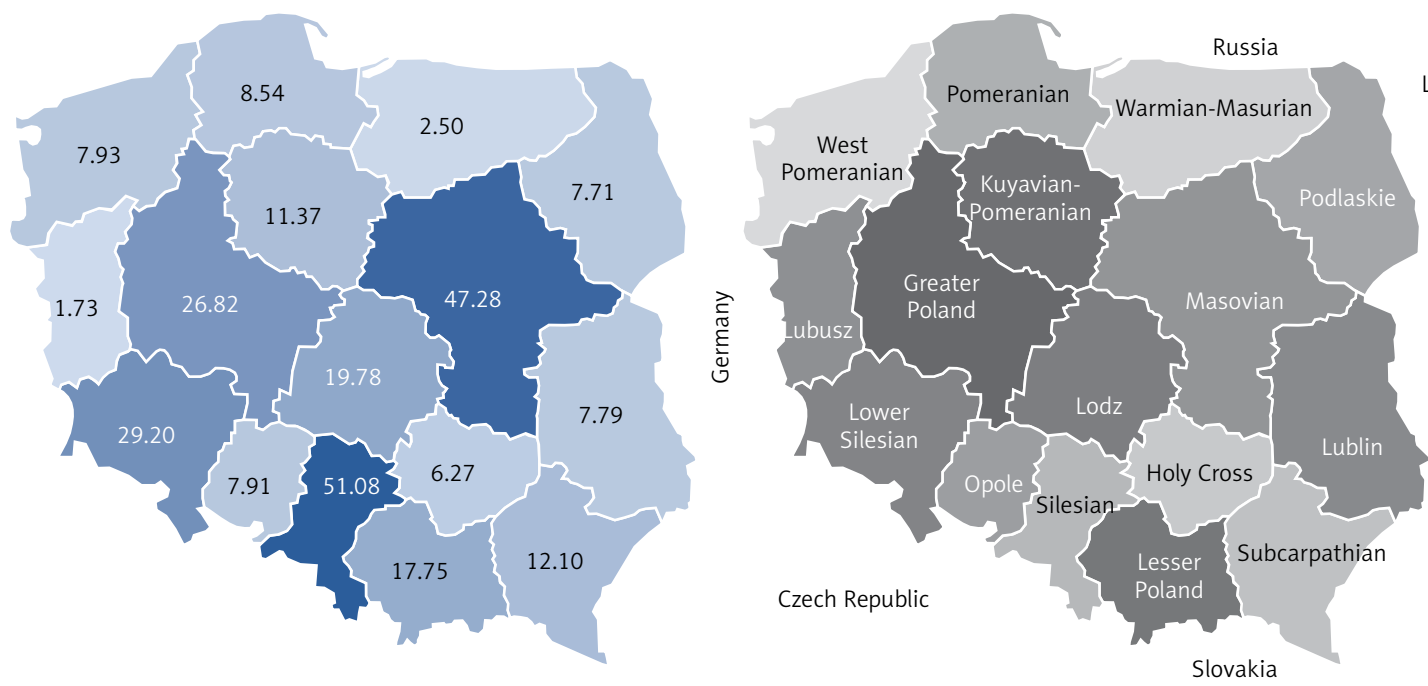

Lithuania

Figure 1. Individual voivodeships and corresponding daily cumulative index (DCI)

observed in Lower Silesian and Silesian voivodeships (5.94 and 5.86, respectively) and the lowest in Lubusz voivodeship (0.89). The highest number of deaths per 10,000 population was reported in the Masovian voivodeship (0.39), whereas Lubusz voivodeship registered no deaths due to COVID-19. The case fatality rate reached the highest values in Masovian (8\%), Opole (7\%) and Subcarpathian (7\%) voivodeships. The highest $\mathrm{DCl}$ value was recorded in Silesian (51.08), followed by Masovian
(47.28), Lower Silesian (29.2) and Greater Poland (26.82) voivodeships (Figure 1).

Table II and Figures 2 and 3 present the results of correlation analyses. All three disease indicators (i.e. incidence rate, mortality rate, case fatality rate) were positively correlated with $\mathrm{DCl}$ and negatively correlated with the number of hospital beds in infectious disease wards per 10,000 population. Additionally, both incidence and mortality rates were positively correlated with population 
Table II. Correlations between incidence, mortality, case fatality rates and selected epidemiological indicators

\begin{tabular}{|lcccccc|}
\hline \multirow{2}{*}{ Parameter } & \multicolumn{2}{c}{ Incidence rate } & \multicolumn{2}{c}{ Mortality rate } & \multicolumn{2}{c|}{ Case fatality rate } \\
\cline { 2 - 7 } & PCC $(p)$ & SRCC $(p)$ & PCC $(p)$ & SRCC $(p)$ & PCC $(p)$ & SRCC $(p)$ \\
\hline DCI & $0.81(0.0001)$ & $0.76(0.001)$ & $0.81(0.0002)$ & $0.83(0.0001)$ & $0.54(0.03)$ & $0.58(0.02)$ \\
\hline Incidence & - & - & $0.79(0.0002)$ & $0.81(0.0001)$ & $0.46(0.076)$ & $0.39(0.137)$ \\
\hline Population density & $0.59(0.017)$ & $0.59(0.016)$ & $0.50(0.049)$ & $0.68(0.004)$ & $0.31(0.236)$ & $0.45(0.077)$ \\
\hline $\begin{array}{l}\text { Case/designated } \\
\text { hospital }\end{array}$ & $0.91(0.0001)$ & $0.90(0.0001)$ & $0.72(0.002)$ & $0.87(0.0001)$ & $0.38(0.141)$ & $0.49(0.053)$ \\
\hline $\begin{array}{l}\text { Infectious diseases } \\
\text { ward beds/10,000 }\end{array}$ & $-0.49(0.055)$ & $-0.54(0.031)$ & $-0.50(0.048)$ & $-0.62(0.011)$ & $-0.56(0.023)$ & $-0.42(0.107)$ \\
\hline Age $>65$ & $0.52(0.040)$ & $0.49(0.055)$ & $0.25(0.346)$ & $0.27(0.316)$ & $-0.26(0.334)$ & $0.11(0.696)$ \\
\hline
\end{tabular}

$D C I$ - daily cumulative index, PCC - Pearson's correlation coefficient, SRCC - Spearman's rank correlation coefficient.

A

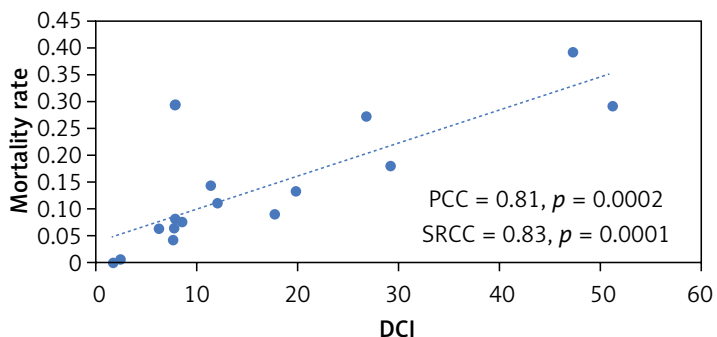

B

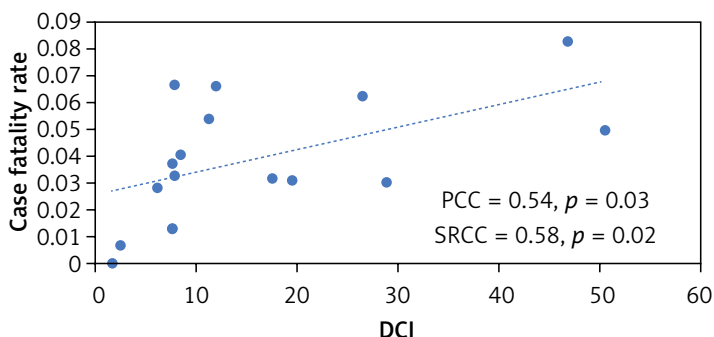

Figure 2. Associations between disease indicators and daily cumulative index (DCI) of COVID-19. A - Correlation between mortality rate and $\mathrm{DCI}$. B - Correlation between case fatality rate and $\mathrm{DCl}$ PCC - Pearson's correlation coefficient, SRCC - Spearman's rank correlation coefficient.

A

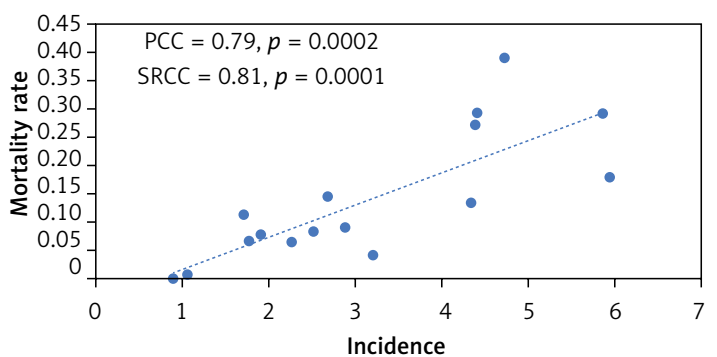

B

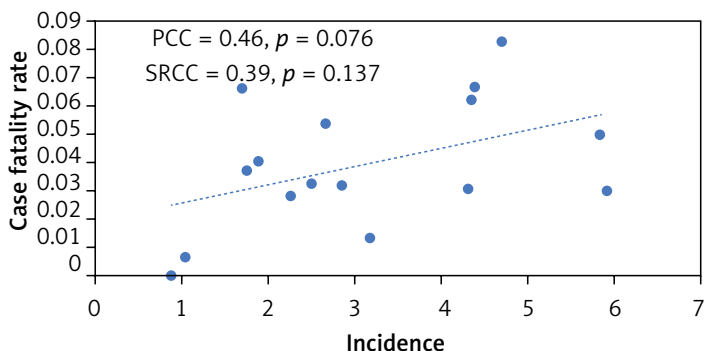

Figure 3. Associations between disease indicators and incidence of COVID-19. A - Correlation between mortality rate and incidence. $\mathbf{B}$ - Correlation between case fatality rate and incidence

PCC - Pearson's correlation coefficient, SRCC - Spearman's rank correlation coefficient.

density and number of cases per COVID-19 designated hospital. Only incidence was found to have a strong positive correlation with the proportion of people aged above 65 . Among variables analyzed in our study, incidence rate, case fatality rate and age > 65 were distributed normally, which justified the use of PCC. However, in most cases the assumptions of PCC were not met and SRCC was more applicable.

No statistically significant correlation was observed between disease indicators and number of beds in general hospitals, proportion of urban population, proportion of medical staff per 100,000 population, number of performed tests per 10,000 population and healthcare system performance indexes.

\section{Discussion}

Although the epidemic outbreak occurred almost simultaneously in individual voivodeships and national lockdown measures were enforced at the same time, our study revealed considerable regional differences in terms of COVID-19 incidence, mortality and case fatality rates. Findings of our correlation analyses indicate that such disparities might be associated with factors related to epidemiology, population characteristics and healthcare resource availability. 
The fact that both incidence and mortality were positively correlated with population density is in line with our knowledge about the spread of the virus and confirms that measures to reduce viral transmission, focusing on social distancing in particular, are reasonable [12-16]. The positive correlation between COVID-19 incidence and the proportion of the population aged above 65 suggests that older adults are more likely to get infected, which has been observed in other countries as well [17-22].

All three disease indicators were found to have a strong positive correlation with $\mathrm{DCl}$. High $\mathrm{DCl}$, i.e. a rapid increase in the number of cases, may speed up the viral transmission in a given population and in consequence the growth of incidence rates. Furthermore, the positive correlation between $\mathrm{DCl}$ and both mortality and case fatality suggests that $\mathrm{DCl}$ could be considered as an indirect indicator of healthcare burden, as a sudden increase in the number of cases causes higher consumption of medical resources and may lead to worse patient outcomes.

Similarly, the negative correlation between number of hospital beds in infectious disease wards per 10,000 population and both mortality and case fatality indicates an association between deaths due to COVID-19 and healthcare resources availability. At the same time, however, a negative correlation between incidence and the number of hospital beds in infectious diseases wards per 10,000 population was observed. This finding may be explained by the fact that mortality is strongly positively correlated with incidence and parameters correlated with mortality are correlated with incidence as well. The lack of association between all three disease indicators and healthcare performance indexes indicates that these indicators are not specific enough to measure the quality of healthcare in the context of COVID-19.

The current pandemic is a novel and rapidly emerging worldwide crisis. To date only a few studies have aimed to examine the potential relationship between COVID-19 and parameters related to epidemiology and availability of healthcare resources. Our results are in line with a previously published study which associates higher number of infections with higher mortality [23]. Our analysis also reveals that both mortality and case fatality are positively correlated with $\mathrm{DCl}$ (Figure 2) [24]. However, contrary to mortality, no positive correlation between case fatality and incidence was found (Figure 3). Acknowledging the potential association of mortality and healthcare resource availability [25] implies that DCl could be used as an indirect indicator of healthcare burden. Still, it is important to stress that mortality due to COVID-19 may be strongly affected by patients' underlying conditions and critical care capacity (number of mechanical ventilators, intensive care units, critical care providers) [17, 26].

The major strength of our study was analyzing individual regions within one country. This ensured that similar epidemic outbreak dates occurred and equal lockdown and diagnostic measures were enforced. However, the results of our study should be interpreted cautiously, bearing in mind limitations attributable to the quality of data available at the time of analysis. The testing strategy is central to obtain actual data on the number of COVID-19 cases, and no country knows the number of infected people, as it depends on how widespread the testing is. Furthermore, due to the lack of current regional data on the number of intensive care units, mechanical ventilators, critical care providers and their potential impact on analyzed COVID-19 indicators, future studies covering these parameters might be valuable.

In conclusion, additionally to incidence rate, $\mathrm{DCl}$ may be used as an indicator of increased COVID-19 mortality and case fatality rates. Mortality and case fatality rates may be affected by healthcare resource availability, and it is therefore crucial to develop strategies aimed at preventing the capacities of the healthcare system being exceeded. According to our results, social distancing and common testing play a vital role in reducing SARS-CoV-2 transmission. The results of our analysis might help political leaders and health authorities to allocate enough medical resources to manage the present pandemic, as well as future pandemics.

\section{Acknowledgments}

Project financed under the program of the Minister of Science and Higher Education called "Regional Initiative of Excellence" in the years 20192022, project no 024/RID/2018/19, amount of financing 11999 000,00 PLN. We thank PO, who provided the model construct.

\section{Conflict of interest}

The authors declare no conflict of interest.

\section{References}

1. Ministry of Health [Accesed 10 May 2020]; available from: https://web.archive.org/web/20200304112521/ https://www.gov.pl/web/zdrowie/pierwszyprzypadek-koronawirusa-w-polsce

2. World Health Organization (WHO); Coronavirus disease 2019 (COVID-19) Situation Report - 50; 5.

3. Nowak B, Szymański P, Pańkowski I, et al. Clinical characteristics and short-term outcomes of patients with coronavirus disease 2019: a retrospective single-center experience of a designated hospital in Poland. Pol Arch Intern Med 2020; 130: 407-11.

4. Ministry of Health [Accesed 14 May 2020]; available from: https://gis.gov.pl/aktualnosci/definicja-przypadku- 
na-potrzeby-nadzoru-nad-zakazeniami-ludzi-nowymkoronawirusem-sars-cov-2/.

5. National Institute of Public Health[Accesed 10 May 2020] available from: https://karta-zgonu.pzh.gov.pl/2020/03/ 27/wazne-wytyczne-dotyczace-okreslania-przyczynzgonow-zwiazanych-z-epidemia-koronawirusa-wywolujacego-covid-19/.

6. Ministry of Health [Accesed 14 May 2020]; available from: https://www.gov.pl/web/koronawirus/wykaz-zarazenkoronawirusem-sars-cov-2.

7. Statistics Poland [Accesed 10 May 2020]; available from https://stat.gov.pl/statystyka-regionalna/publikacjeregionalne/system-regionalnych-opracowan-analitycznych/wojewodztwo-podregiony-powiaty-gminy/].

8. Kozierkiewicz A, Natkaniec M, Megas B, Gilewski D, Ignatowicz M, Waśko B. PWC. Health Care Fitness Index 2018; 11-13.

9. Ministry of Health [Accesed 10 May 2020]; available from: https://www.gov.pl/web/koronawirus/lista-szpitali.

10. Central Statistical Office. Health and Health care in 2016. 82.

11. Voivodeship Office [Accesed 4 March 2020]; available from: https://www.gov.pl/web/gov/uw.

12. Burlacu A, Mavrichi I, Crisan-Dabija R, et al. "Celebrating old age": an obsolete expression during the COVID-19 pandemic? Medical, social, psychological, and religious consequences of home isolation and loneliness among the elderly. Arch Med Sci 2020. DOI: https://doi. org/10.5114/aoms.2020.95955.

13. Milne GJ, Xie S. The Effectiveness of Social Distancing in Mitigating COVID-19 Spread: a modelling analysis. medRxiv 2020. doi: https://doi.org/10.1101/2020.03. 20.2004005 .

14. Knapik P, Knapik M, Trejnowska E, et al. Should we admit more patients not requiring invasive ventilation to reduce excess mortality in Polish intensive care units? Data from the Silesian ICU Registry. Arch Med Sci 2019; 15: 1313-20.

15. Prem K, Liu Y, Russell TW, et al. The effect of contro strategies to reduce social mixing on outcomes of the COVID-19 epidemic in Wuhan, China: a modelling study. Lancet Public Heal 2020; 5: 261-70.

16. Sjödin H, Wilder-Smith A, Osman S, Faroog Z, Rocklöv J. Only strict quarantine measures can curb the coronavirus disease (COVID-19) outbreak in Italy, 2020. Eurosurveillance 2020; 25: pii=2000280.

17. Petretto DR, Pili R. Ageing and COVID-19: what is the role for elderly people? Geriatr 2020; 5: 25.

18. Zhou F, Yu T, Du R, et al. Clinical course and risk factors for mortality of adult inpatients with COVID-19 in Wuhan, China: a retrospective cohort study. Lancet 2020; 395: 1054-62.

19. Piątek $Ł$, Wilczek K, Kurzawski J, et al. Gender-related disparities in the treatment and outcomes in patients with non-ST-segment elevation myocardial infarction: results from the Polish Registry of Acute Coronary Syndromes (PL-ACS) in the years 2012-2014. Arch Med Sci 2020; 16: 781-8.

20. Cismaru A, Cismaru L, Nabavi S, et al. Game of "crowning" season 8: RAS and reproductive hormones in COVID-19 - can we end this viral series? Arch Med Sci 2020. DOI: https://doi.org/10.5114/aoms.2020.96604.

21. Katsiki N, Banach M, Mikhailidis D. Lipid-lowering therapy and renin-angiotensin-aldosterone system inhibitors in the era of the COVID-19 pandemic. Arch Med Sci 2020; 16: 485-9.
22. Bianconi V, Bronzo P, Banach M, Sahebkar A, Mannarino $M$, Pirro $M$. Particulate matter pollution and the COVID-19 outbreak: results from Italian regions and provinces. Arch Med Sci 2020; 16: 985-92.

23. Lai CC, Wang CY, Wang YH, Hsueh SC, Ko WC, Hsueh PR. Global epidemiology of coronavirus disease 2019 (COVID-19): disease incidence, daily cumulative index, mortality, and their association with country healthcare resources and economic status. Int J Antimicrob Agents 2020; 55: 105946

24. Lai CC, Wang CY, Wang YH, Hsueh PR. Global coronavirus disease 2019: What has daily cumulative index taught us? Int J Antimicrob Agents 2020; 55: 106001.

25. Ji Y, Ma Z, Peppelenbosch MP, Pan Q. Potential association between COVID-19 mortality and healthcare resource availability. Lancet Glob Heal 2020; 8: e480.

26. Remuzzi A, Remuzzi G. COVID-19 and Italy: what next? Lancet 2020; 395: 1225-8. 